\title{
REVISTAMARACANAN
}

\section{Cinema e História: olhares sobre a imigração no Brasil - desconstruindo estereótipos}

\author{
Cinema and History: views on immigration in Brazil - deconstructing stereotypes
}

\author{
Sylvia Nemer \\ Universidade do Estado do Rio de Janeiro \\ nemer.sylvia@gmail.com
}

\begin{abstract}
Resumo: Entre as décadas de 1970 e 2000, um conjunto de filmes brasileiros se voltou para a representação da figura do imigrante contrapondo-se às visões estereotipadas acerca da presença estrangeira no Brasil extensamente difundidas nos produtos culturais de consumo popular, como foi o caso do cinema entre as décadas de 1940 e 1950, quando as telas atuaram como repetidoras dos discursos hegemônicos, por via de regra, pautados no pressuposto da integração, adaptação e convivência harmoniosa entre estrangeiros e sociedade local. Essa visão "cordial" começa a ser problematizada a partir da afirmação de um novo cinema no Brasil; um cinema político, engajado, interessado em desconstruir mitos envolvendo processos históricos plurais como, por exemplo, a imigração, tema dos filmes analisados no presente texto.
\end{abstract}

Palavras-chave: Experiências de imigração; Fronteiras; Deslocamentos; Representações de imigrantes pelo cinema; Relações entre cinema e história.

\begin{abstract}
Between the 1970s and the 2000s a set of Brazilian films turned to the representation of the immigrant's figure in a way opposed to the stereotypical views about the foreign presence in Brazil, widely broadcast in the popular consumption of cultural products as in the cinema between the decades of 1940 and 1950, when the screens acted as repeaters of hegemonic discourses as a rule, based on the assumption of integration, adaptation and harmonious coexistence between foreigners and local society. This "cordial" vision begins to be criticized by the establishment of a new cinema in Brazil; an engaged political cinema, interested in deconstructing myths associated to collective historical processes, such as immigration, the common theme of the films reviewed in this text.
\end{abstract}

Keywords: Immigration, frontiers; displacement; immigrants in the cinema; relationships between cinema and history.

Artigo recebido para publicação em: Outubro de 2015 Artigo aprovado para publicação em: Janeiro de 2016 
temática da imigração entra na pauta do cinema brasileiro no contexto da oposição à ditadura militar, quando um olhar diferenciado sobre a figura do imigrante começa a se manifestar na cinematografia nacional na qual surgem obras importantes interessadas em refletir a respeito do tema em uma perspectiva crítica. Essa produção se contrapõe às visões estereotipadas acerca da presença estrangeira no Brasil, extensamente difundidas nos produtos culturais de consumo popular como foi o caso do cinema entre as décadas de 1940 e 1950, quando os musicais carnavalescos produzidos pelos estúdios brasileiros e as produções internacionais rodadas no país dominaram as telas nacionais reproduzindo largamente os clichês em circulação nos discursos hegemônicos, por via de regra, pautados no pressuposto da integração, adaptação e convivência harmoniosa entre estrangeiros e sociedade local. Essa visão "cordial" começa a ser problematizada a partir da afirmação de um novo cinema no Brasil; um cinema político, engajado, interessado em desconstruir mitos envolvendo processos históricos plurais, como, por exemplo, a imigração, até então ausente ou tratada de forma unilateral e superficial tanto na filmografia nacional quanto nos filmes estrangeiros ambientados no país.

Testemunhando as múltiplas experiências vivenciadas pelos imigrantes no processo de adaptação ao novo ambiente, os filmes nacionais que abordam a questão oferecem retratos representativos da realidade da imigração no Brasil cujos processos diferem radicalmente dos experimentados por outros países afetados pelo fenômeno migratório como, por exemplo, a França e os EUA onde as preocupações relacionadas à presença, em larga escala, de imigrantes ilegais têm motivado uma produção extensa de filmes focalizando essa temática nas últimas décadas.

Apesar de constituir um corpus pouco extenso em comparação com a produção francesa e a norte-americana, o conjunto de filmes brasileiros produzidos sobre o tema da imigração a partir dos anos 1970 é bastante representativo das problemáticas envolvendo os processos migratórios em curso no país, em diferentes períodos históricos, ou seja, a imigração em massa promovida pelo Estado ou particulares entre meados do século XIX e início do século XX, a imigração familiar ou individual entre as duas guerras mundiais e a imigração como retorno às origens no contexto atual.

\section{Em busca da "terra prometida"}

Motivo fundamental da imigração em massa de europeus e orientais para as Américas na virada do século XIX para o XX, a pobreza, que obrigou milhares de japoneses a abandonarem seu país em busca da terra prometida, é o ponto de partida do filme de Tizuka Yamasaki "Gaijin: caminhos da liberdade" ${ }^{1}$ cuja cena de abertura focaliza um grupo de

\footnotetext{
${ }^{1}$ Gaijin: caminhos da liberdade, de Tizuka Yamasaki, Brasil, 1980.

2 PRADO, Maria Ligia Coelho. "Gaijin. Os caminhos da liberdade: tempo e História". In: SOARES, Mariza de Carvalho e FERREIRA, Jorge. (Orgs.). A História vai ao Cinema. Rio de Janeiro, Record, 2001. p. 99110.
} 
camponeses de uma região extremamente pobre do Japão fazendo planos de deixar o país em busca de um futuro melhor no Brasil.

A agricultura brasileira, após o fim da escravidão, vivia uma séria crise de mão de obra que se tentava superar com a vinda de imigrantes através de programas promovidos pelo Estado ou por particulares. O filme denuncia esse sistema, mostrando a exploração do trabalho dos imigrantes japoneses que, chegando ao Brasil, vão para uma fazenda de café em São Paulo onde, além de viverem e trabalharem em condições desumanas, não conseguem tirar qualquer proveito do salário recebido, utilizado, unicamente, para ressarcimento dos custos da viagem e compras no armazém da propriedade que reproduz o ciclo da exploração através da arbitrariedade exercida nos preços e no peso das mercadorias. Infelizes, mal alimentados e presos à fazenda por endividamento, os imigrantes representam um enorme benefício para o fazendeiro que enriquece graças ao trabalho dessa mão de obra quase escrava. Do ponto de vista do imigrante, o que sobra é a constatação de que o sonho da terra prometida não passava de uma ilusão.

A história da imigração pode conter também narrativas de sucesso no país de adoção. É o caso de "O quatrilho", ${ }^{3}$ filme de Fábio Barreto ${ }^{4}$ baseado no livro homônimo de José Clemente Pozenato. A história se passa em 1910, numa comunidade rural no Rio Grande do Sul habitada por imigrantes italianos. Esse tipo de imigração, diferentemente da representada no filme de Yamasaki, faz parte da política do governo imperial de criação de núcleos coloniais de pequenos proprietários, num prosseguimento da velha ideia colonizadora, inaugurada por $D$. João VI, com a fundação de Nova Friburgo. A imigração italiana e alemã no Rio Grande do Sul se inscreve nesse projeto voltado para o preenchimento de vazios demográficos e a consolidação das fronteiras no Sul do país. Além dessa função estratégica e geopolítica, a imigração foi planejada como um processo de substituição não só do trabalho escravo pelo trabalho livre, mas, principalmente, como substituição do negro escravo pelo branco europeu em um processo de colonização baseado na pequena propriedade.

O enredo gira em torno da trajetória de dois casais de imigrantes italianos que se unem sob o teto de uma mesma casa. O tempo faz com que a esposa de um, Teresa, se interesse pelo marido da outra, Mássimo. Ambos decidem fugir e começar uma nova vida, deixando para trás seus parceiros Ângelo e Pierina. Em São Paulo, Mássimo e Teresa formariam uma nova família e veriam prosperar os negócios da marcenaria por eles fundada. Ângelo e Pierina ficaram desesperados com o abandono dos respectivos cônjuges, mas, por razões práticas, resolveram se unir maritalmente. Por "viver em pecado", o casal enfrentaria a hostilidade dos vizinhos e do padre. Mas, como seus negócios prosperassem cada vez mais, ambos alcançariam o perdão da igreja e da comunidade. "O quatrilho" coloca em cena a imigração sob o ponto de vista de uma comunidade tradicional de imigrantes italianos que vê seus valores ameaçados pela conduta moralmente repreensível de alguns de seus membros. 0

\footnotetext{
3 PESAVENTO, Sandra Jatahy. "De razões e sentimentos: O quatrilho na tela". In: SOARES, Mariza de Carvalho e FERREIRA, Jorge. (Orgs.). A História vai ao Cinema. Rio de Janeiro, Record, 2001. p. $217-$ 235.

${ }^{4}$ O quatrilho, Fábio Barreto, Brasil, 1995
} 
desvio, porém, não representa a ruptura da ordem dominante, recomposta, no final, pela formação de duas novas famílias e o enriquecimento dos dois casais.

\section{Identidade e alteridade}

Bem diferente de "O quatrilho" é a história narrada em "Lavoura arcaica", longametragem dirigido por Luiz Fernando Carvalho ${ }^{5}$ com base na obra de Raduan Nassar. Também centrado no embate entre a violação dos códigos de conduta e a manutenção da identidade do grupo, o filme conta a história de uma família libanesa vivendo no Brasil em uma propriedade rural com exíguos contatos com o mundo exterior. Não há referência ao tempo nem alusão ao lugar onde se desenrola a narrativa. Toda a trama gira em torno da relação com a tradição cujo elemento central é a família, profundamente afetada pelo comportamento de André, um filho desgarrado que sai de casa devido à severa lei paterna e ao sufocamento da ternura materna. Seu irmão mais velho o traz de volta, mas, ao retornar, André irá irromper os alicerces familiares ao se apaixonar por sua irmã, Ana. A tentativa radical dessa família de preservar a cultura das origens será frustrada, na medida em que o relacionamento entre os irmãos representará, ao contrário de "O quatrilho", uma ruptura com a ordem tradicional, violada pelo interdito do incesto e pela ameaça à continuidade do grupo.

"Lavoura arcaica" lida com a questão da imigração na perspectiva da experiência do imigrante em sua busca inesgotável de reprodução da cultura de origem no novo destino. 0 isolamento, o fechamento em relação às influências externas e a recusa à integração ao país de acolhida são aspectos que envolvem, de forma mais ou menos significativa, os processos migratórios, independentemente dos contextos de origem ou destino. No que se refere ao filme, a independência em relação ao contexto histórico é uma opção evidente. A temática da imigração, embora perpasse o enredo, não é objeto da narrativa que foge do específico do tema para considerá-lo em um plano universal com destaque para a questão da identidade considerada sob o prisma do apego doentio às tradições originárias da terra natal.

Ao universo fechado, quase sufocante, de "Lavoura arcaica" se contrapõe a amplidão dos espaços percorridos pelo fotógrafo libanês Benjamin Abraão através do sertão nordestino em busca de imagens inéditas de Lampião e seu grupo. Baseado em uma história real, 0 longa-metragem "Baile perfumado" de Paulo Caldas e Lírio Ferreira, ${ }^{6}$ coloca em cena a figura de um típico imigrante libanês reconhecido pela sua profissão característica de mascate, atividade que define o personagem do filme ambientado no interior do Nordeste, na década de 1930. Nessa época, que coincide com a desintegração do Império turco-otomano após o fim da Primeira Guerra, dá-se a segunda grande leva de imigrantes árabes para o Brasil. A primeira, havia ocorrido na virada do século XIX para o XX, quando os imigrantes sírios e libaneses se fixaram em diferentes pontos do país fundando colônias que prosperaram graças ao comércio da borracha e do café. Desse modo, os recém-chegados não tinham problemas para encontrar

\footnotetext{
${ }^{5}$ Lavoura arcaica, Luiz Fernando Carvalho, Brasil, 2001.

${ }^{6}$ Baile perfumado, Paulo Caldas e Lirio Ferreira, Brasil, 1996.
} 
trabalho, pois os imigrantes já fixados agenciavam-nos como mascates, fornecendo-lhes mercadorias. A partir daí, o imigrante passa a estabelecer contatos com populações de diferentes pontos do país, ampliando o seu leque de relações e promovendo um rico intercâmbio comercial e cultural com a sociedade local. No caso de Benjamin Abraão, o contato foi com os cangaceiros que, contradizendo o que costumavam afirmar os jornais e as revistas da época, não eram avessos ao progresso e à modernidade. Ao contrário, costumavam não apenas usufruir do consumo de bens associados à vida moderna, mas também utilizá-los para promover a imagem do grupo, como foi o caso das fotos e dos filmes produzidos por Benjamin Abraão documentando o cotidiano do cangaço no período que antecede a sua extinção em 1938.

Em "Baile perfumado", as ideias de deslocamento, de trocas culturais, de movimento incessante em direção ao outro colocam em evidência uma dimensão da experiência da imigração bastante diferente da focalizada no enredo de "Lavoura arcaica" cujo destaque é o apego visceral à família e às tradições. Essa dupla perspectiva pode ser observada em dois outros filmes relacionados a processos migratórios, "Aleluia Gretchen" ${ }^{7}$ de Silvio Back ${ }^{8} \mathrm{e}$ "Cinema, aspirinas e urubus" de Marcelo Gomes, ${ }^{9}$ que tratam da imigração alemã no Brasil, no contexto da Segunda Guerra.

O filme de Back narra a saga de uma família alemã no Sul do Brasil, ao longo de quatro décadas, entre os anos de 1930 e 1970. Os Kranz chegam ao país nas vésperas da Segunda Guerra fugindo de perseguições políticas na Alemanha, então dominada pelo nazismo. Motivo da imigração, o pai, Ross, é um liberal convicto cujo posicionamento crítico em relação ao totalitarismo alemão contrasta fortemente com a posição dos demais membros da família, em especial, da mãe, Lotte, que atua como uma alegoria da mãe-pátria Alemanha. Figura central da narrativa, Mami exerce dominação sobre todo o grupo concentrado no Hotel Flórida que será o negócio dos Kranz no Brasil. Nesse espaço circunscrito, a família, isolada da sociedade local, tenta reproduzir o seu velho mundo.

O contexto histórico focalizado em "Aleluia Gretchen" se repete em "Cinema, aspirinas e urubus" no qual a figura do imigrante alemão Johan coloca novamente em cena as relações entre Brasil e Alemanha no período das ditaduras hitlerista e varguista. O filme se passa em 1942, quando a posição do governo brasileiro na Segunda Guerra Mundial reverte a favor dos Aliados. Nesse quadro, a posição dos nacionais, muitos dos quais identificados com o integralismo, torna-se menos tolerante em relação ao nazismo, tal como destaca a segunda parte de "Aleluia Gretchen", ambientada nos anos 1940, momento em que a mudança nos rumos da guerra repercutirá no cotidiano da família Kranz cuja tranquilidade passará a ser sistematicamente ameaçada pelas violentas represálias da polícia.

No caso de Johan de "Cinema, aspirinas e urubus", a posição crítica em face do nazismo não impede que ele seja visto com desconfiança pelos brasileiros sugestionados pela

\footnotetext{
7 MAGALHÃES, Marion Brephol. "Aleluia Gretchen: um hotel para o Reich". In: SOARES, Mariza de Carvalho e FERREIRA, Jorge. (Orgs.). A História vai ao Cinema. Rio de Janeiro, Record, 2001. p. 31-42

${ }^{8}$ Aleluia Gretchen, Silvio Back, Brasil, 1976.

${ }^{9}$ Cinema, aspirinas e urubus, Marcelo Gomes, Brasil, 2005.
} 
extensa propaganda antigermânica promovida pelos veículos de comunicação após a declaração de guerra do Brasil à Alemanha. Para evitar confrontos, Johan decidirá circunscrever sua trajetória ao sertão nordestino onde, como representante da Bayer, se encarregará de difundir o famoso remédio para dor de cabeça. Consigo, ele leva uma tela e um projetor de cinema e, em cada parada, exibe, ao lado de documentários sobre a pujança de São Paulo, pequenos filmes publicitários sobre o seu produto. Ao longo do caminho, ele dá carona a várias pessoas, entre as quais Ranulfo que passará a ajudá-lo em troca de algum dinheiro visando à sonhada viagem para o Rio de Janeiro.

O filme de Marcelo Gomes inverte vários clichês não apenas no que se refere à figura do imigrante alemão, representado sob o prisma do pacifismo em tempos de guerra, mas também do nordestino que se propõe a migrar para o Sudeste a fim de ter contato com pessoas diferentes dos seus conterrâneos, vistos negativamente pelo personagem que deseja não só fugir da miséria mas também viver experiências como aquelas apresentadas nos filmes exibidos pelo seu companheiro de viagem.

Como em "Baile perfumado", o cinema, representando a modernidade introduzida no sertão pelo imigrante, é o ponto de partida de uma transformação. Em "Cinema, aspirinas e urubus", Ranulfo é objeto dessa transformação vivenciada interiormente a partir da sua convivência com o estrangeiro e dos sentidos provocados pelas imagens por ele veiculadas. No caso de "Baile perfumado", a imagem fotográfica e cinematográfica repercute como um fenômeno de transformação social, na medida em que a introdução da câmera no meio do bando de cangaceiros acabará por facilitar o trabalho das volantes no sentido da localização e do extermínio de Lampião e seu grupo.

Absolutamente centrais nos dois filmes ambientados no sertão, as noções de alteridade e porvir, embora veementemente recusadas pelas famílias de imigrantes libaneses e alemães representadas em "Lavoura arcaica" e "Aleluia Gretchen", não deixam de se revelar nos respectivos filmes cuja preocupação desmesurada com a preservação das tradições herdadas dos antepassados é questionada no desdobramento trágico das duas tramas que apontam para a impossibilidade do passado reproduzir-se no futuro; em um caso, pela relação entre irmãos que impede a propagação da prole, em outro, pela morte da pequena Gretchen que frustra a possibilidade de se criar uma nova Alemanha em solo brasileiro. Nas duas narrativas, a negação da alteridade apresenta-se como afirmação da deriva no lugar em que se constituiria a identidade.

Assim, a temática do deslocamento, da viagem, da relação com o outro, presente nas narrativas de "Baile perfumado" e "Cinema, aspirinas e urubus", não teria como contraponto radical a ideia de uma antiviagem sugerida por "Lavoura arcaica" e "Aleluia Gretchen". Ao contrário, a experiência da imigração parece implicar, nesses filmes, na imersão no universo do outro que se dá independentemente do desejo individual ou coletivo de se preservarem os laços com a comunidade original através do encerramento do grupo no seu microcosmo particular. Tal constatação se apresenta na sequência final de "Aleluia Gretchen" quando, já 
nos anos 1970, a família se reúne em uma festa em que todos dançam embalados pelo som da Cavalgada das valquírias misturada a ritmos de rock e de samba carioca.

Os quatro filmes promovem a desconstrução de múltiplos significados associados aos processos migratórios, em geral, enquadrados em estereótipos de identidades envolvendo as diferentes nacionalidades. O que se revela nesse conjunto de obras, principalmente quando consideradas em uma perspectiva comparada, é que imigrantes oriundos de um mesmo contexto histórico e cultural, assumem relações diferenciadas com o país de acolhida: o modo de vida da família libanesa representada em "Lavoura arcaica" difere radicalmente do adotado pelo fotógrafo Benjamin Abraão de "Baile perfumado"; o mesmo acontece com a família alemã de "Aleluia Gretchen" em relação ao vendedor de remédios de "Cinema, aspirinas e urubus". Nessas narrativas, a experiência da imigração assume perspectivas plurais, variando entre alteridade e identidade, tradição e transformação, ilusão e desilusão.

\section{Brasil real e Brasil ideal}

Elemento de destaque na filmografia sobre imigração, a contradição entre Brasil real e Brasil ideal é tema do longa-metragem "Lost Zweig" dirigido por Silvio Back ${ }^{10}$ que, mais de vinte anos após a realização de "Aleluia Gretchen", volta a tratar da presença estrangeira no Brasil, no período da Segunda Guerra. O filme baseado na obra de Alberto Dines Morte no paraíso: a tragédia de Stefan Zweig é inspirado na história real do escritor austríaco que viveu exilado no Rio de Janeiro, entre 1940 e 1942, quando se suicidou junto com a mulher, Lotte, na casa em que moravam, na cidade de Petrópolis. Autor do livro que se transformou em epíteto nacional, Zweig foi acusado de colaborar com a ditadura do Estado Novo em troca de um visto para permanecer no país. Para seus detratores, a visão idealizada apresentada no livro era absolutamente incompatível com a realidade brasileira. Brasil, o país do futuro é uma ode ao país enorme que parecia, com sua imensa energia e vitalidade, capaz de neutralizar a onda de horrores que se espalhara pela Europa. O filme de Back coloca em cena essas contradições típicas da visão de um estrangeiro que, deixando para trás uma terra arrasada pela violência, se confronta com um paraíso, recusando-se a enxergar as suas mazelas. Poderosa e, ao mesmo tempo, frágil, a utopia imaginada por Zweig desmoronou quando a guerra chegou às portas do país cujas ambiguidades ele não conseguiu reconhecer. Para enfrentar o desengano, a morte se transforma na única saída possível.

"Lost Zweig" gira em torno da trajetória de um artista perdido de si mesmo. Traumática, a tomada de consciência da sua condição de estrangeiro em um país cujo conhecimento se construíra a partir de uma visão mitificada, tem um desfecho trágico. Com um final diferente, mas com argumento bastante semelhante, o longa "Tempos de paz", coloca em cena a figura de um imigrante polonês que chega ao Brasil logo depois do fim da Segunda Guerra, quando as autoridades encarregadas de emitir vistos ainda aguardavam por "novas

\footnotetext{
${ }^{10}$ Lost Zweig, Silvio Back, Brasil, 2002.
} 
diretrizes em tempos de paz". Esse é o título da peça teatral de Bosco Brasil que deu origem ao filme dirigido por Daniel Filho. ${ }^{11} \mathrm{O}$ roteiro é focado no diálogo entre o ator polonês, Clausewitz, que chega ao Brasil com a imagem de um país perfeito, livre dos horrores presenciados na Europa durante a guerra e o inspetor da alfândega, Segismundo, um extorturador que cumpre, sem questionamento, as ordens recebidas dos seus superiores. A chegada do polonês acontece em uma fase de transição em que a guerra já havia terminado, mas novas regras quanto à entrada de imigrantes ainda estavam pendentes. $O$ encontro entre os dois personagens torna evidente o abismo existente entre o homem culto, que aprendera português por sonhar em um dia viver no Brasil, e o outro, cujo único preparo foi aprender a obedecer o que the era ordenado. Na fala de Segismundo inscreve-se a chocante constatação de que o Brasil estava muito longe de ser o país idealizado por Clausewitz que, no final, depois de conseguir vencer o desafio lançado pelo oficial, levando-o às lágrimas, obtém o tão sonhado visto.

A produção cinematográfica focada na experiência de imigrantes sírio-libaneses e provenientes da Europa central entre as décadas de 1930 e 1940 coloca em relevo a questão da perseguição de minorias políticas, étnicas e religiosas nos países afetados pelos conflitos armados que se espalharam pelo hemisfério Norte na primeira metade do século XX. Os abalos decorrentes dessa conjuntura tiveram consequências no mundo todo, afetando países não diretamente envolvidos nos conflitos. O Brasil, então sob o poder da ditadura Vargas, vacilou entre o apoio aos países do Eixo e os reunidos no bloco Aliado ao qual o governo brasileiro acabou aderindo, formalmente, em 1942, quando o país declarou guerra à Alemanha. As relações do Brasil com os países em guerra assumiram diferentes posturas dependendo da fase em que se encontrava o conflito. Foram elas que determinaram o tipo de tratamento concedido aos imigrantes provenientes de territórios inimigos sobre os quais as autoridades no poder exerceram um rigoroso controle, como sugerem alguns dos enredos analisados.

\section{0 retorno às origens}

A filmografia brasileira, apesar de não muito extensa quanto ao tema da imigração, levanta importantes discussões concernentes aos processos históricos em curso na primeira metade do século $\mathrm{XX}$, quando as políticas migratórias no Brasil foram extremamente duras em relação à entrada e permanência de imigrantes em solo nacional. Totalmente diferente é o pano de fundo dos filmes ambientados na virada do século XIX para o XX, quando a política de imigração brasileira atuou favoravelmente à entrada de imigrantes no país. Todas essas correntes migratórias tiveram fundamental importância na composição demográfica do Brasil cuja população, no final do século XX, somava um número considerável de brasileiros, filhos ou netos de imigrantes de diferentes nacionalidades. São eles que vão definir a problemática da imigração no Brasil entre os anos 1990 e 2000, época em que se dissemina, entre jovens

\footnotetext{
${ }^{11}$ Tempos de paz, Daniel Filho, Brasil, 2009.
} 
descendentes de imigrantes, a ideia de revisitar as origens dos antepassados, tal como focalizado nos filmes "Terra estrangeira"12 e "Passaporte húngaro"13.

Importante produção do "cinema da retomada", o longa de Walter Salles e Daniela Thomas trata da solidão vivida pelos imigrantes em uma cidade como São Paulo onde, em um pequeno apartamento, bem em frente ao viaduto Presidente Costa e Silva, o Minhocão, moram a costureira Manuela e seu filho Paco que sonha em ser ator de teatro. Manuela, por sua vez, alimenta o antigo desejo de voltar à terra de seu pai, San Sebastian, no país basco ${ }^{14}$. A inflação e os juros altos praticados no país dificultam a realização dos planos da viagem, adiada até que as economias acumuladas em sua poupança lhe permitissem custear a passagem. É com esse quadro que se inicia "Terra estrangeira" que coincide com o começo do governo Collor tragicamente inaugurado com o anúncio feito pela ministra Zélia Cardoso de Mello do bloqueio de todas as aplicações financeiras, incluindo a poupança dos brasileiros. Em frente ao aparelho de TV, Manuela assiste estarrecida ao pronunciamento. Ao chegar do teatro onde ensaiara uma interpretação de Hamlet, Paco encontra a mãe morta estendida na poltrona. O sonho de revisitar a terra do pai lhe fora arrancado pela brutal realidade imposta pelo Estado que, sintomaticamente, começava a pregar a redução de suas funções e a autoorganização da sociedade. O projeto neoliberal de uma economia de mercado livre das interferências do poder público contrastava fortemente com a ação autoritária e arbitrária do governo sobre os investimentos privados dos cidadãos. A morte de Manuela, após o confisco de suas economias duramente acumuladas em tempos de inflação, representa a derrota de uma minoria cujos sonhos são sistematicamente cassados pelas palavras e ações dos mais fortes. Trata-se da morte simbólica do Brasil como sociedade marcada pela falta de perspectivas para os jovens que não conseguem se sentir em casa nesse ambiente de frustração e extrema decadência. Órfão dessa situação, Paco alimenta o sentimento de viver em uma "terra estrangeira". Sem dinheiro, descrente do futuro, ele aceitará viajar para Portugal levando uma encomenda valiosa: um violino Stradivarius dentro do qual, sem que ele saiba, estava escondido um tesouro em diamantes. Chegando a Lisboa, a missão que lhe parecera fácil, mostra-se extremamente complicada e perigosa, obrigando-o a fugir e buscar abrigo em lugar seguro. Em seu caminho para cruzar a fronteira com a Espanha, aparece Alex, outra brasileira perdida em terras portuguesas. Os dois seguirão juntos rumo a San Sebastian compartilhando uma aventura intensa de paixão e de fuga dos contrabandistas. Na perseguição ao casal, um tiro acaba acertando Paco que agoniza no colo de Alex, enquanto o carro se aproxima de San Sebastian.

"Terra estrangeira" é um filme ligado a acontecimentos imediatos situados na era Collor. O enredo se inscreve em uma realidade recente da história do Brasil ao mesmo tempo

\footnotetext{
12 Terra estrangeira, Walter Salles e Daniela Thomas, Brasil , 1996.

13 Passaporte húngaro, Sandra Kogut, Brasil , 2002.

14 NEMER, Sylvia. "Cinéma-terre: militantisme politique et national dans le cinema brésilien". In: SANTOS, Idelette Muzart-Fonseca dos e ROLLAND, Denis. (Org.). La terre au Brésil de I'abolition de I'esclavage à la mondialisation. Paris, L'Harmattan, 2006. p. 213-225.
} 
que remete ao nosso passado colonial, representado por Portugal onde nos deparamos com brasileiros tentando ganhar a vida e angolanos discriminados. À medida que acompanhamos as aventuras de Paco e Alex pelas ruas de Lisboa e pelas estradas que conduzem à fronteira com a Espanha, mais forte se torna nosso sentimento de desencanto, de desterro, transferido da tela para os espectadores que compartilham as mesmas experiências melancólicas vivenciadas pelos personagens. As mortes que pontuam o enredo, de Manuela no início do filme e de Paco no final, simbolizam não apenas a destruição dos sonhos acalentados pela fração mais desprotegida da sociedade brasileira. Para além disso, elas representam a falência do Brasil como país do futuro.

À morte como estratégia simbólica, em "Terra estrangeira", ou como opção efetiva, no caso de Stefan Zweig, outra saída se apresenta como alternativa à desilusão reinante no Brasil durante as últimas décadas do século passado. Sonho de muitos brasileiros, a conquista de um passaporte europeu é o tema de "Passaporte húngaro", único documentário incluído entre os filmes considerados nesta análise. O filme liga duas pontas da história da imigração no Brasil. Em uma delas estão os avós que deixam a Hungria devido à perseguição dos nazistas aos judeus na Segunda Guerra; em outra, Sandra, descendente da família Kogut que se fixa no Brasil, onde nascerão os filhos e os netos. Sandra deseja tirar um passaporte húngaro, mas, para isso, terá que cumprir uma série de formalidades burocráticas visando garantir sua condição de descendente de imigrantes provenientes da Hungria. O documentário coloca em cena uma prática que se tornou comum no Brasil, a partir dos anos 1980, quando o aprofundamento da crise econômica atravessada pelo país associada às mudanças geopolíticas na Europa (avanço do processo de integração europeia e queda do Muro de Berlim) provocou um movimento intenso de busca pelas nacionalidades de origem, algumas, como a húngara, até então, pouco atraentes em termos de imigração. Nesse contexto, uma parcela considerável de descendentes de imigrantes europeus passou a procurar os laços de ligação com seus antepassados. A Europa que, em diferentes contextos nos séculos XIX e XX, atuara como ponto de partida de imigrantes para o Brasil se torna polo de atração de filhos e netos desses europeus nascidos em solo brasileiro. O mesmo acontece em relação ao movimento de descendentes de japoneses, os nisseis e sanseis, voltando à terra de seus antepassados. ${ }^{15}$

A questão do retorno trabalhada em "Passaporte húngaro" coloca em evidência um movimento duplo que, de um lado, procura retraçar as rotas dos imigrantes europeus vindos no passado para o Brasil e, de outro, busca refletir sobre o problema na perspectiva do presente, marcado pela expectativa dos descendentes de conquista da cidadania dos pais ou avós oriundos de países com economias mais estáveis e oportunidades mais favoráveis de emprego e sucesso profissional.

\section{Cem anos de história e histórias}

${ }^{15}$ PRADO, Maria Ligia Coelho. Op. cit. 
O século $X X$ foi marcado pelo movimento de múltiplas correntes migratórias que atravessaram o oceano em busca de uma vida melhor em terras brasileiras. Fechado esse círculo, a história conquista o cinema que transforma em imagens as ricas experiências vividas pelos imigrantes nos processos de integração à cultura e à sociedade brasileira. Os problemas sociais e as mentalidades que perpassam os enredos nos colocam diante de traços relevantes dessa história. Contudo, a dimensão histórica das obras não permite que elas sejam consideradas como expressão direta da realidade representada. O cinema é uma arte e, como tal, não pode ser tomado como meio de informação ou veículo de comunicação. Suas representações são construções simbólicas nas quais os acontecimentos são postos em perspectiva para serem interpretados. É, portanto, indispensável tentar verificar nos filmes o tipo de problemática que se oferece à interpretação. Nos filmes considerados nesta análise, a problemática comum é a existência de fronteiras não apenas políticas e geográficas, mas, sobretudo, fronteiras psicológicas erguidas entre os imigrantes e o país de acolhida. ${ }^{16} \mathrm{O}$ que os seus personagens realizam, menos que o deslocamento de um país para outro, é uma viagem interior na qual se deparam com um mundo onde tudo que se afirma é o estranhamento. À fronteira geográfica, material, se substitui de imediato uma distância moral reconstruída a cada instante, a cada etapa do processo migratório. É isso que focalizam, de forma mais ou menos direta, os filmes sobre imigração produzidos no Brasil, a partir da década de 1970, quando se inicia a realização de uma série de obras abordando, com um viés crítico, as experiências de imigrantes em diferentes contextos históricos entre o final do século XIX e a época atual.

Sylvia Nemer: Doutora em Comunicação pela UFRJ (2005) e Doutora em História pela PUCRIO (2012). Desde 2010, atua no Departamento de História da UERJ como professora visitante da área de História do Brasil (2010-2015) e, atualmente, como pesquisadora Pós-doc vinculada ao LABIMI com o projeto "Cinema e imigração". É autora de O cordel no cinema de Glauber Rocha: relações intertextuais, Edições Casa de Rui Barbosa, 2007 e Feira de São Cristóvão: a história de uma saudade, Casa da Palavra, 2011.

${ }^{16}$ SERCEAU, Michel. "Faux mouvement: les thèmes de la frontière et du voyage dans le cinema beur et dans quelques films maghrébins" In: GRUNERT, Andrea (dir.). Op. cit., p. 88-95. 